\title{
Interpreting Arguments
}

\author{
JONATHAN BERG University of Haifa
}

We often speak of "the argument in" a particular piece of discourse. Although such talk may not be essential to philosophy in the philosophical sense, it is surely a practical requirement for most work in philosophy, whether in the interpretation of classical texts or in the discussion of contemporary work, and it arises as well in everyday contexts wherever we care about reasons given in support of a claim. (I assume this is why developing the ability to identify arguments in discourse is a major goal in many courses in informal logic or critical thinking-the major goal when I teach the subject.) Thus arises the question, just how do we get from text to argument?

I shall propose a set of principles for the extrication of arguments from argumentative prose. In so doing, I aim to provide both a (meta) philosophical theory about a central part of the philosophical routine and also some practical guidelines suitable for students of argument. First I shall present the theoretical framework underlying my remarks, and then, after an exposition of the principles, I shall show how they apply to some questions about implicit premises and about ignoratio elenchi.

\section{Theoretical Preliminaries}

I take an argument or inference to be a collection of claims, one of which, the conclusion, is put forth as following from the others, the premises. While not distinguishing strictly between arguments and inferences, I think of inferences as atomic arguments, in which none of the premises double as conclusions inferred from any of the other premises.
Two notions which would merit extensive analysis in a broader context will only get a bit of clarification here. By 'claims' I mean what are variously called 'propositions', 'statements', or 'contents'. I remain neutral with regard to their ontological status and shall not pretend to know exactly how to individuate them, especially in relation to sentences. I shall assume that for every claim there is at least one literal, declarative sentence typically used for making that claim, and often I shall not distinguish between the claim, proper, and such a sentence.

What I mean when I say that one claim follows from other claims is much harder to specify than what I do not mean. I certainly do not have in mind any mere psychological or causal connection. Nor do I wish to restrict myself to deductive validity. I shall rely for now on a very rough normative formulation: one claim follows from another (or others) if one should not accept the latter without accepting the former. And an argument is valid (as opposed to deductively valid, in the usual sense) if its conclusion does, indeed, follow from its premises. ${ }^{1}$

\section{Arguments and Intentions}

A more noteworthy feature of arguments as conceived here is their intentionality. An argument is not merely a collection of claims, nor even a collection of claims bearing a certain logical relation to each other, but rather, a collection of claims intended, by an arguer, to bear a certain logical relation to each other. ${ }^{2}$ This is not to say that we can speak of an argument only relative to some actual arguer, for we can always 
imagine, for the sake of discussion, a hypothetical arguer with the requisite intentions (much as we can discuss a speech act, such as the assertion that $p$, without regard to any actual speaker). But whether the arguer be actual or hypothetical, the structure of an argument (as well as the content) is largely determined by the arguer's intentions.

Consequently, extracting arguments from their textual surroundings is a matter of discerning intentions. And how those intentions are to be discerned depends, of course, on our intentions as interpreters. In philosophical discussion the point of recounting an argument is to enable its evaluation, with regard to both its validity and also the acceptability of its premises-or at least I shall assume this as a working hypothesis. That is, I take it that I am not unusual among philosophers in intending when elucidating an argument to facilitate judgment of its soundness. ${ }^{3}$ Of course, I may have the ulterior motive of wanting to impart a particular attitude toward the argument, but I must nevertheless at least make out to be presenting the argument for the sake of objective evaluation (as I would want the attitude I favor to be seen as the inevitable result of fair and fitting consideration).

Thus construed, the interpretation of argumentative discourse is like the interpretation, for the sake of critical review, of any expository prose, in that in both cases we aim to determine on the basis of the text (and its context) what the author meant, so that a decision may then be reached about its correctness. It should come as no surprise, then, that the principles of interpretation I formulate apply not only to argumentative discourse, but to any discourse being interpreted in preparation for the assessment of its descriptive content.

The application of these general principles to argumentative discourse is especially valuable for several reasons. First of all, when the extrication of arguments is treated as a kind of interpretation, more attention is paid to the arguer's intentions, which otherwise tend to be neglected as attention centers on strict logical validity. As I shall try to show, giving the arguer's intentions their due can shed some light on certain issues in the theory of argument interpretation. Secondly, general principles of interpretation cannot be applied to argumentative discourse without special attention to validity, due to its centrality in the enterprise of argument. Above all, the principles I present here constitute a reasoned, unified basis for argument interpretation, applying systematically to all aspects of the interpretive processas opposed to, for instance, ad hoc rules for determining implicit premises.

\section{Principles of Interpretation}

The following principles are put forth as guidelines for presenting the argument contained in a given text, where the argument is to be presented by giving sentences corresponding to its claims and by indicating, via these sentences, which claims allegedly follow from which. Such a presentation often takes the form of a numbered list of sentences along with a tree diagram of the sentence numbers which indicates the lines of inference, but any method of presenting a set of sentences under a partial order will do.

I view these principles as mere guidelines, because they are not hard and fast rules; indeed, they are largely overdeterminate. Hence, all except the last should be understood as implicitly qualified by a certain paribus operator. Furthermore, they are by no means meant to provide a complete method for extricating arguments. Rather, they are intended to help in the application of more basic strategies for identifying the elements of an argument's structure, by contributing to the resolution of questions raised by these more fundamental strategies about how a particular claim should be formulated and how it functions in the argument. ${ }^{4}$ 
(a) The Principle of Loyalty: Be loyal to the text (written or spoken-in formulating claims prefer the wording of the text, and in general prefer interpretations supported by the strongest, most direct textual evidence (including what is known of the circumstances under which the text was produced).

The text, after all, is the entire manifestation of the argument; it is, in a sense, all the interpreter has to go on. Since the text completely exhausts the arguer's explicit commitments, deviation from it increases the interpreter's vulnerability to charges of misinterpretation. And the interpretation is fatally flawed to the extent that the arguer can say it is not what he meant. ${ }^{5}$ This applies not only to the formulation of the argument's claims, but also to the determination of the lines of inference. The word 'therefore' is strong, direct textual evidence in support of taking the claim immediately after it as allegedly following from the claim(s) before it; mere juxtaposition may also suggest such a link (though with no hint of the direction of the inference), but it would be much weaker, less direct evidence.

(b) The Principle of Clarity: Present the argument as clearly as possible-be literal, precise, and terse.

This obvious infringement on-or restriction of-the Principle of Loyalty follows from the hypothesis that the point of recounting the argument is to facilitate its proper evaluation. For surely it is easier to assess claims and inferences when they are clearly put. ${ }^{6}$ Resolving conflicts between principles will be discussed below with the last principle.

(c) The Principle of Neutrality: Formulate the claims in neutral terms.

Again, the point is to facilitate the argument's proper evaluation, on the assumption that claims can be more judiciously assessed stripped of logicaly extraneous emotional charges. Compare, for instance,

The murderer who executes a poor, defenceless fetus must bear full responsibility for his wicked crime.

with

An individual who performs an abortion must bear full responsibility for his action.

(d) The Principle of Charity: Assume the arguer is not grossly deficient in either general knowledge or logical competence, i.e., that he would not make wildly absurd claims or inferences.

This follows more or less from the assumption that the argument in question is worth considering, which should be assumed at least for the sake of discussion. ${ }^{7}$ This principle is much more modest than many of its popular namesakes, for it is aimed at pulling out of the text the arguer's argument, which is not always the best argument that can be read into the text. ${ }^{8}$

(e) The Principle of Principled Preference: The preferability of the favored interpretation over rejected competing interpretations must be justifiable in terms of the principles above; hence, alternative interpretations that cannot be dismissed so must not be neglected.

This principle deals with the overdeterminacy of the others. As noted above, the principles are overdeterminate in that they may conflict-various principles may support various incompatible interpetations. Such conflicts call for subjective judgment, weighing the relative pull of the various principles along with the grounds for their application and the circumstances under which the argument is being discussed. Facing a conflict between the Principles of Loyalty and Clarity, for instance, we weigh the clarity gained by a particular reformulation of the arguer's words against the risk of misinterpretation incurred by the requisite deviation from the text; and this involves taking into account the abilities and interests of our intended audience, e.g., how clear the relevant expressions are to them, and how important for them is faithfulness to the original text. Clearly one interpretation may be favored in the class- 
room and quite another in a professional journal. And even with the same audience different interpretations may be preferred in accordance with, for example, whether the discussion is primarily historical or topical. In any case, the Principle of Principled Preference requires that the choice of interpretation ultimately be based in this way on the other four principles. Sometimes, of course, such deliberations will be inconclusive, in which case there is no choice but to present all of the equally acceptable alternatives. ${ }^{9}$

In the remaining sections I shall bring these principles to bear on specific issues concerning implicit premises and ignoratio elenchi.

\section{Implicit Premises}

Often-perhaps typically-not all the claims in an argument are set forth explicitly. I do not have in mind cases where a claim is merely presented by name, as in

Due to the law of supply and demand, investors should carefully study prevailing market conditions before investing in a particular product.

or by some nonpropositional construction, as in

By the tatoo on his arm, we can infer that he is a sailor.

I mean to consider, rather, cases in which one (or more) of an argument's premises is not stated (or mentioned) at all. This raises two questions. First, why think that there are such claims? If an arguer does not make a certain claim, why consider it part of his argument? Secondly, even if there are implicit premises, how do we decide in particular cases what they are?

In response to the first question a strict textualist would simply deny that there ever are any (entirely) implicit premises. According to the textualist view, by throwing in so-called implicit premises the interpreter constructs an argument which must be distinguished from the one given by the arguer. In some cases the addition of an implicit premise will yeild a stronger argument, in which the conclusion is better supported by the premises. But distinguishing between different arguments for the same conclusion on the basis of how much support the premises provide is fundamental to the whole enterprise of assessing arguments. In other cases the addition of an implicit premise will yield a weaker argument, depending on commitment to a more questionable claim. But distinguishing between arguments on the basis of the acceptability of their premises is also crucial to argument assessment. The new, expanded argument may well be worth considering, especially if there is good reason to believe that the arguer would endorse it. Nevertheless, it cannot be taken as the arguer's argument, as long as it contains claims not appearing in the arguer's text.

The problem with the textualist tack lies, not surprisingly, in the undue weight it places on the text. While surely a distinction is to be made between the argument without any implicit premises added and the argument with, the question remains, which of these two arguments is the arguer's? Although the Principle of Loyalty points to the first, the Principle of Charity prohibits attributing to the arguer any gross nonsequitur; hence, the need for attributing implicit premises. ${ }^{10}$ This does not mean, of course, that the Principle of Loyalty should be ignored. Indeed, as will be seen shortly, it severly constrains ascriptions of implicit premises, requiring overriding evidence for each implicit premise posited. However, keeping in mind the importance of the arguer's intentions, as described above, we must not remain stuck to the text when the arguer's intentions clearly transcend it. The point may be more evident with regard to implicit conclusions, the existence of which seems beyond question, but it applies to implicit premises 
just as well.

Given that there are implicit premises, how do we identify them? ${ }^{11}$ Were we solely concerned with patching up non-sequiturs, the surest way to proceed would be by adding as an implicit premise to every inference that is not deductively valid the validating conditional of the inference, formed by the conjuction of the inference's premises as antecedent and the conclusion of the inference as consequent. ${ }^{12}$ Since the validity of any inference is equivalent to the truth of its validating conditional, the validating conditional is implicit in the inference in at least the sense that the arguer is as committed to its truth as he is to the validity of the inference. ${ }^{13}$

But the attribution of validating conditionals as implicit premises is neither called for nor even condoned by the principles of interpretation. The principle of Charity does not make it the interpreter's business to eliminate all nonsequiturs-only gross ones. So where there are no gross flaws in an argument, the Principle of Charity provides no justification for riding roughshod over the Principle of Loyalty by adding anything implicit. And even when a nonsequitur is gross enough to activate the Principle of Charity, it can be dealt with, among other ways, by adding an implicit premise that merely makes it tolerable, rather than by making the inference deductively valid.

So the principles of interpretationin particular, the Principle of Charitydo not generally require taking unstated validating conditionals as implicit premises. Moreover, they may be seen as not even allowing it. For if two interpretations of an argument differ only in that one includes a validating conditional as an implicit premise where the other does not, then they are equally informative, attributing to the arguer the very same commitments (due to the aforementioned equivalence between the validity of the inference and the truth of its validating conditional). And so, for the sake of terseness, the Principle of
Clarity would favor the interpretation lacking the superfluous implicit premise. Whatever might have been said about that implicit premise could just as well be put in terms of the validity of the inference. ${ }^{14}$

Of course, nothing I have said should be construed as a general ban against taking validating conditionals as premises. To whatever extent the text indicates that the arguer actually intended a validating conditional as a premise, i.e., as one of the claims from which a conclusion is inferred, the Principle of Loyalty requires presenting it as such. ${ }^{15}$ But because of the very same principle, no unstated claim, whether validating or not, may be thrown in without good reason.

To be included as an implicit premise a claim must meet certain criteria deriving from the principles of interpretation. First of all, insofar as the Principle of Charity provides that justification for attributing implicit premises in spite of the Principle of Loyalty, implicit premises must enhance the inference's validity. That is, there should be more reason to accept the conclusion when the premises of the inference are augmented by the implicit premise than when they are taken alone. ${ }^{16}$

Secondly, out of respect for the Principle of Loyalty, there must be sufficient reason for thinking that the implicit premise is indeed held by the arguer. ${ }^{17}$ Such reason may derive from the text, directly or indirectly, from information about the author, including other texts he has produced and the circumstances under which he wrote, and even from general background knowledge. Failure to satisfy this criterion may give rise to arguments against a straw man. ${ }^{18}$

At this point John Nolt adds his version of the Principle of Charity: "If several different sets of premises satisfy criteria (1)-(3) [the author expects us to take them for granted, they strengthen the reasoning, and they do not merely embody a stated inference], add the premise or set of premises which make 
the argument strongest" (p. 101). Just what this amounts to is not clear. On the one hand Nolt stresses how this principle respects the author's intentions, directing us "to assume that he or she made the best possible case for the conclusion within the bounds of what was actually stated" (p.101), and "to construct the best possible argument within what we know of the author's intentions" (p. 102). But on the other hand, he justifies the principle on the grounds that "if we sincerely want to know whether the conclusion is true, then it is in our interest to examine the strongest argument possible-even if it isn't exactly what the author had in mind" (p. 101, emphasis mine). Now if our aim is to find out whether the conclusion is true, the author's intentions do not matter at all; in such circumstances we should consider whatever plausible arguments we can think of for or against the conclusion, including those not even suggested by the text. If, however, our aim is, as Nolt says, to determine "which argument the author intended" (p. 102), then the bounds of his intentions must not be violated at all. Nolt claims that his Principle of Charity merely tells us how to choose among possible implicit premises all of which the author intended to be taken for granted. But if the author intended them all to be taken for granted, there is no reason to choose between them-the interpretation should include all intended premises. The need to choose can arise only when it is not clear what the author intended, in which case the Principle of Principled Preference directs us to offer all interpretations that cannot be ruled out by the other principles.

In actual practice our ascription of implicit premises is restricted further by a criterion of questionability-to the extent that an implicit premise is generally accepted we tend not to bother mentioning it. ${ }^{19}$ One way to account for this would be by loosening the notion of validity so that it would be relative to uncontroversial general knowledge. That is, we could say that one claim follows from another (or others) if, given what is generally known and not in question, one should not accept the latter without accepting the former. Alternatively, avoiding such a nonstandard notion of validity, we can justify the omission of trivial implicit premises on conversational grounds: uncontroversial implicit premises are not mentioned simply because they are not interesting.

\section{Ignoratio Elenchi}

Sometimes an arguer argues beside the point, trying to get his conclusion accepted by making a claim from which follows, at best, some related but significantly different conclusion. I classify it as a case of ignoratio elenchi when the arguer does this deliberately, recognizing (at least upon reflection) the discrepancy between the apparent conclusion and the plausible conclusion. This differs from standard characterizations of ignoratio elenchi in two important ways. First, I do not count as ignoratio elenchi honest errors in reasoning, but only cases where the arguer is aware (at least upon reflection) that he is arguing beside the point; there must be logical malice aforethought. Secondly, instances of ignoratio elenchi are by my definition fallacious. They do not include, for example, legitimate arguments ad hominem. ${ }^{20}$

Ignoratio elenchi so understood has no place in argument; instances of it never belong to the argument proper. For insofar as the arguer realizes that a claim does not really support his conclusion, he cannot intend it as such. ${ }^{21}$ So however effective a rhetorical device it may be, it is not part of the argument (in the favored sense).

Furthermore, to the extent that an argument is clearly beside the point, and hence, obviously fallacious, it would be uncharitable to interpret the arguer as truly arguing that way, since the Principle of Charity is formulated in terms of logical acumen and not moral scruples. 
That is, from a logical point of view it is better to be called a logically competent cheat than an honest fool. The upshot of this is that ad hominems and the like should not, when cleary fallacious, even be considered part of the argument. ${ }^{22}$

If this result seems extreme, that is because it is. For I am urging that we purge from our conception of the argument in a text what has traditionally been a major part of informal logic; that much of what is typically called "argument ad such-and-such" is not really argument at all. But this is exactly what follows from my stated conception of an argument as a collection of claims intended by the arguer to be such that one follows from the others. It was on the basis of this view of argument, along with some minor assumptions about the point of reporting arguments, that $I$ arrived at the principles of argument interpertation presented above. Just as these principles were applied in the previous section to yield some results on the formulation of an argument's implicit premises, they are applied here to a problem in the formulation of an argument's bounds. Given the conception of argument from which the principles derive, it is natural that they place insincere rhetorical devices beyond the bounds of the argument proper, despite how much such devices superficially resemble argumentation.

\section{Notes}

2 Govier's definition makes this intentionality fairly explicit: "An argument is a set of claims that a person puts forward in an attempt to persuade an audience that some further claim is true. . A person who argues. . gives some reasons intended to back up her view" (p. 1).

3 Cf. Thomas: "my aim in studying logic is not so much to refute other people's arguments as it is to find the truth through reasoning" (p. 19). This leads to a reconstructionist approach to the interpretation of arguments, putting more weight on the argument's strength than on the arguer's intentions. See below on Loyalty and Charity.

4 Some such strategies: (a) locate inference words (such as 'therefore') and identify the claims they link; (b) list all the claims in the text, and then determine which are given in support of which; (c) determine the conclusion and work backwards-identify the claims from which the conclusion is most directly inferred, then identify the claims from which those claims are inferred, and so on, down to unsupported premises.

This is a trivial consequence of my conception of arguments as ordered by the arguer's intentions. As valuable as it is to consider arguments suggested by a text, even in the spirit of the text, this is to be distinguished from interpreting the argument given. As Nolt puts it, "we must try to divine the author's thoughts. An argument, after all, is its author's creation" ( $p$. 99). Cf. Scriven: "The principal function of argument analysis is not that of reconstructing the state of mind or body of beliefs of the arguer. . .You need to decide whether you are arguing against the arguer or the argument $^{\prime \prime}$ (p. 85). (I would describe the choice as between discussing the arguer's argument and discussing other arguments for the same conclusion.) For a full exposition of this crucial distinction between the arguer's argument and the best argument compatible with the text, including reasons for aiming in interpretation at the former, as I do, see Govier's "Uncharitable Thoughts About Charity" and "On Adler on Charity."

6 Thomas: "When reasoning contains unclear language, we often must 
clarify it in order to evaluate the reasoning" (p. 163). Govier reasons similarly:

In order to understand the exact line of argument that someone is using, it is helpful to set out the premises and conclusion in a simple standard format. . . To standardize an argument is to set out its premises and conclusion in clear, simple English statements. . Standardizing arguments gives us a clear version of where they are going and forces us to look carefully at what the arguer has said. When we come to the more interesting stage of criticizing arguments, we will find standardizing extremely helpful. (Page 21)

Govier requires standardization only if the argument is not worded in a "relatively simple and straightforward way" (p. 144), which may be no less than what the Principle of Clarity requires, depending on what counts as "relatively simple and straightforward." I assume her demand for English statements was meant to apply only to English standardizations.

7 I believe this is the idea behind Jonson's proposal that "charity begin at home," i.e., that "our obligations under the Principle of Charity... should be honored only in the case of real and serious arguments" (pp. 8-9).

8 Cf. Thomas, pp. 18-9, Scriven, pp. 71 $f$. See notes 3 and 5 above.

\section{Cf. Govier:}

If you are working on an argument, trying to construct a diagram, and you find that several distinct models are plausible, it is ... a real possibility that both models are in some sense "right" interpretations, even though they differ from each other in some respects. In this situation you should work with the diagram that seems to fit the passage best, while noting that your interpretation of the argument's structure is not the only plausible one.

Contra Govier, I explicitly insist on having the choice between models based on the given principles of interpretation, and on working with all models whose implausibility cannot sufficiently be established in this way (such sufficiently being relative, of course, to the context of the analysis). Also, my remarks apply not only to the argument's structure, but to its claims, as well.

10 Thus, the implicit premises of which I speak are what Ennis calls "gapfillers" as opposed to "back-ups" (pp. 62-3).

11 As indicated above (see notes 3, 5, and 8), I am concerned with identifying the implicit premises in the arguer's argument. Those who prefer to consider other arguments, typically stronger than the arguer's, will construe the search for implicit premises differently, as they are searching for implicit premises in other arguments. (I believe this is the distinction Ennis means to capture by distinguishing between "used" and "needed" assumptions, pp. 63 f.) For examples of the latter see Scriven, pp. $162 \mathrm{ff}$., Thomas, pp. 253 ff., Ennis, pp. 64-6 and 69 ff., Hitchcock, pp. 89 ff., and Burke.

12 For the sake of discussion we may include in the category of validating conditionals suitable quantified variants, such as the universal generalization of the conditional described. Regarding such premises in argument reconstruction, as opposed to interpretation, see Hitchcock.

13 Grice suggest that the validating conditional can be conventionally implicated (pp. 44-5). Cf. van Eemeren and Grootendorst.

14 See Govier on "reconstructed" arguments, pp. 123 ff., and Scriven, pp. 84 and 163-4; but cf. Thomas, p. 260 . I have been considering the treatment of validating conditionals as implicit premises ony in inferences that are not deductively valid. Concerning the extension of such a policy to all inferences, see Carroll.

$15 \mathrm{Cf}$. Nolt, who, though arguing on 
grounds similar to mine, infers the stronger, general conclusion, that "it is pointless to add any premise which merely embodies a stated inference" ( $p$. 101). If our aim in attributing implicit premises is, as Nolt says, "to fill in the author's thoughts" (p. 99), then we must allow for cases in which the author seems to be thinking of the validating conditional.

16 Nolt: "Add premises only if they strengthen the reasoning" (p. 99). Cf. Scriven: "the assumptions have to be strong enough to make the argument sound" (p. 85). This can be right only if one is not restricting one's attention to the arguer's argument.

17 Nolt: "Add only statements which the author would have intended to be taken for granted" (p. 99). As Govier sums it up, "no supplementation without justification" (p. 33). I believe that such deference to the Principle of Loyalty is what underlies Gough and Tindale's view of hidden premises as extracted from the text rather than added to it. Cf. Thomas, pp. $253 \mathrm{ff}$.

18 See Govier on the Straw Man fallacy, p. 109.

19 Ennis: "in order that the activity be perceived to be significant, I generally ask for implicit assumptions that in addition someone might challenge" (p. 62). Govier recognizes the obviousness of a claim as a reason for not mentioning it in an argument ( $p$. 37 ); I am offering it as a reason for not mentioning the claim even in the analysis of the argument.

20 For an excellent discussion of the ad hominem fallacy see Govier's "Ad Hominem: Revising the Textbooks."

21 The relevant sense of support is as something done by claims, not people.

22 What I am urging can be seen as an application of Johnson's second cor- ollary to Scriven's Principle of Charity: "If a sub-section of a passage already identified as an argument contains obviously bad reasoning and if it can be interpreted as "clutter" (extraneous to the argument), then one should disregard that sub-section in the final analysis" (p. 5); where ignoratio elenchi is viewed as clutter. Ironically the example Johnson gives to demonstrate how the Principle of Charity regulates the ascription of implicit premises.

Premise: $\mathrm{X}$ is a person of bad character.

Conclusion: $X^{\prime}$ 's views about the press and the media are invalid,

is what I would classify as ignoratio elenchi, hence, "clutter," hence, non-argument.

\section{References}

Burke, Michael, "Unstated Premises." Informal Logic, 7 (1985), 107-118

Carroll, Lewis. "What the Tortoise Said to Achilles," Mind, (1895).

van Eemeren, Frans H., and Rob Grottendorst. "Unexpressed Premises: Part I. Journal of the American Forensic Association, 19 (1982), 97-106.

van Eemeren, Frans H., and Rob Grootendorst. "Unexpressed Premises: Part II." Journal of the American Forensic Association, 19 (1983), 215-25.

Ennis, Robert H. "Identifying Implicit Assumptions." Synthese, 51 (1982), 61-86

Gough, James, and Christopher Tindale. "'Hidden' or 'Missing' Premises." Informal Logic, 7 (1985), 99-106.

Govier, Trudy, "Ad Hominem: Revising the Textbooks." Teaching Philosophy, 6 (1983), 13-24.

Govier, Trudy. "On Adler on Charity." Informal Logic Newsletter, 4 (1982), 10-1.

Govier, Trudy. A Practical Study of Argument. Belmont: Wadsworth, 1985. 